REVISTA DE GESTÃO ESECRETARIADO

MANAGEMENT AND ADMINISTRATIVE

PROFESSIONAL REVIEW
Organização: SINSESP

Editora Científica: Dra. Rosimeri Ferraz Sabino

Avaliação: Double Blind Review pelo SEER/OJS

Revisão: Gramatical, normativa e de formatação

Data de recebimento do artigo: 01-08-2018

Data de aceite do artigo: 11-03-2019

\title{
Mobilidade internacional profissional: uma revisão bibliométrica
}

\author{
Ágson Aquino Zago \\ Graduado em Administração pela Universidade Federal de Uberlândia (UFU). \\ E-mail: agson_zago@hotmail.com (Brasil)
}

Carlos Roberto Domingues

Doutor em Administração de Empresas pela Fundação Getúlio Vargas (FGV-EAESP). Professor na graduação e na pós-graduação da Universidade Federal de Uberlândia (UFU).

E-mail: carlos.domingues@ufu.br (Brasil)

Adrianne Marina dos Santos Silva

Graduanda em Administração na Universidade Federal de Uberlândia (UFU) e graduada em

Design pela UFU. E-mail: adrianne.marina@gmail.com (Brasil)

\section{Resumo}

O debate sobre mobilidade internacional de profissionais e suas implicações para as empresas e para os indivíduos apresenta-se como um tema atual e importante. Assim, a sistematização do que tem sido pesquisado e quem são os principais autores são questões fundamentais para que o campo venha a ser melhor compreendido. O presente artigo teve por objetivo a realização de uma pesquisa bibliométrica, com um recorte nos Estudos Organizacionais Interculturais, com trabalhos publicados em periódicos nacionais que relatam o processo de mobilidade internacional. Foram analisados 53 artigos encontrados nas bases de dados Portal de Periódicos Capes e Spell, entre os anos 2000 e 2017, os quais foram escolhidos pela significância dos achados nesse período. Por meio da análise desses artigos, chegou-se à conclusão que o número cada vez maior de pesquisas produzidas denota o crescente interesse e a relevância do tema, ainda que esse número seja baixo quando comparado com os de bases internacionais. Observou-se, também, uma evolução dos assuntos relacionados ao assunto: desde a preocupação inicial sobre os elementos motivadores e o papel da família no processo de mobilidade, passando por questões mais processuais e chegando à discussão sobre a importância desse tipo de mobilidade profissional para a estratégia das empresas. Observaram-se, por fim, lacunas a serem exploradas e discutidas sobre os tipos de mobilidade internacional e as configurações organizacionais que têm surgido por transformações também da área de Recursos Humanos.

Palavras-Chaves: Bibliometria. Gestão de Expatriados. Mobilidade. Mobilidade Internacional. Recursos Humanos. 


\title{
International professional mobility: a bibliometric review
}

\begin{abstract}
The debate on international professional mobility and its implications for companies and individuals presents itself as a current and important theme. Thus, the systematization of what has been researched and who are the main authors are fundamental questions for the field to be better understood. The present article aimed of carrying out a bibliometric research, with a cut in Intercultural Organizational Studies, with papers published in national journals that report the international mobility process. We analyzed 53 articles found in the Capes and Spell Periodical Portals databases between 2000 and 2017, chosen for the significance of the findings in this period. Through the analysis of these articles, it was concluded that the increasing number of researches produced denotes the growing interest and relevance of the theme, although this number is still low compared to international bases. There was an evolution of subjects related to the theme: from the initial concern about the motivating elements and the role of the family in the international mobility process, through more procedural issues and the discussion about the importance of this type of professional mobility to the strategy of the companies. There were gaps to be explored and discussed about the types of international mobility and the organizational configurations that have arisen through transformations also in the area of Human Resource Management.
\end{abstract}

Keywords: Bibliometrics. Expatriate Management Human Resources. International Mobility. Mobility.

\section{Como referenciar em APA:}

Zago, A. A., Domingues, C. R., \& Silva, A. M. dos S. (2019). Mobilidade internacional profissional: uma revisão bibliométrica. R.G.Secr.,GESEC, 10(1), 119-140.

\section{Como referenciar em ABNT:}

ZAGO, A. A.; DOMINGUES, C. R.; SILVA, A. M. S. Mobilidade internacional profissional: uma revisão bibliométrica. R.G.Secr.,GESEC, São Paulo, v. 10, n. 1, p. 119-140, jan.-abr. 2019.
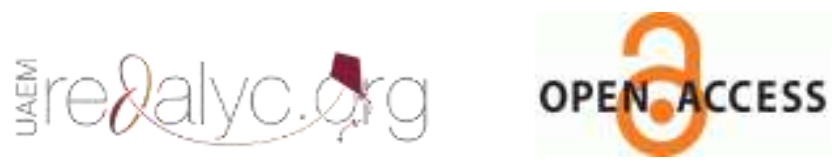


\section{Introdução}

Nos últimos vinte anos a mobilidade de profissionais tornou-se um importante disseminador de conhecimentos e inovação para o desenvolvimento das empresas que implementaram esse processo. O que antes era tido como uma "fuga de cérebros", agora é mais um fator estratégico usado pelas organizações para angariar maiores resultados financeiros e aprimorar o ambiente intraorganizacional.

Conforme afirmam Bueno e Freitas (2015), a evolução da tecnologia de informação e de comunicação auxiliou na expansão da atuação das organizações dentro e para além de suas fronteiras domésticas. Isso, por sua vez, tem gerado um deslocamento dos seus profissionais com alta qualificação para outras nações, com o intuito de sanar a falta de empregados qualificados locais. Desse modo, surgem os chamados expatriados profissionais que, hoje, também, se colocam nessa realidade para ascender na carreira (Spanger, 2012). Quando há o retorno desses profissionais ao local de origem, eles passam a ser chamados de repatriados.

Em meio a essa realidade, a área de Recursos Humanos tenta discernir os padrões que surgem das experiências dos profissionais que tiveram ou estão tendo uma imersão internacional. A partir daí o setor modifica as suas políticas e práticas, para que os atores globais possam se adaptar às novas culturas de maneira benéfica para a empresa e para o indivíduo. Em outras palavras, surgem novos subsistemas de Recursos Humanos com a denominação de Gestão de Recursos Humanos Internacional e Gestão de Expatriados, no intuito de abarcar a responsabilidade sobre os processos relacionados ao envio dos profissionais para o exterior, de modo que seja possível fazer da prática de expatriação uma estratégia organizacional.

Decorrente dessa situação, o que se percebe é que as pesquisas realizadas com o objetivo de desvelar os mais diferentes efeitos, tanto sobre as organizações como sobre as pessoas, estão pulverizadas ao longo do tempo e em diversos meios de publicação. Quando um tema começa a se tornar relevante, é necessário tanto para os estudantes como os pesquisadores que ele seja sistematizado e analisado como um todo para socializar a sua estrutura de produção em um determinado período de tempo. Assim, observando a importância de se voltar ao que já foi escrito e sistematizar as contribuições nacionais sobre o tema, realizou-se um levantamento bibliométrico 
que trata da mobilidade internacional profissional em artigos publicados em periódicos brasileiros no período de 2000 a 2017. Este período foi definido a partir das pesquisas de levantamento que apresentaram o incremento e significância nas publicações somente a partir de 2000.

A importância desta pesquisa reside na organização da produção científica sobre o assunto que pode servir para o entendimento de como este tema tem sido trabalhado, além de viabilizar o desenvolvimento de uma agenda de estudos futuros.

\section{Referencial Teórico-Empírico}

A globalização ou mundialização (na definição dos franceses) gera uma série de mudanças no campo social, resultantes do ato de deslocar-se, em nível mundial e individual (Beck, 1999). Especificamente sobre a internacionalização de empresas, Bueno (2010) considera que ela pode ser realizada de diferentes formas, mas visa, a priori, a expansão da organização a fim de explorar e conquistar mercados. É nesse contexto organizacional que Bueno e Freitas (2015) consideram que a mobilidade de pessoas ganhou maior peso e evidência nas últimas décadas, perante o progresso da economia dos países, da concepção de blocos econômicos e do crescimento da importância das corporações para a sociedade. Quando tratadas as formas de mobilidade, Freitas (2009) descreve que é possível haver três. A primeira, de capitais, representada pela variedade de transações bancárias e financeiras. A segunda, organizacional, acontece quando empresas inteiras se deslocam. Já a última, profissional, ocorre quando há o deslocamento de pessoas em função de trabalho e de suas carreiras, também denominada de expatriação.

O processo de expatriação abrange todas as pessoas que moram por um tempo ou para sempre em um país diferente daquele onde nasceram (González \& Oliveira, 2011). Todavia, por conotar alguém sem pátria (expatriado) e carregar consigo uma série de situações diferentes, alguns pesquisadores e também profissionais nas empresas preferem usar os termos mais neutros: mobilidade profissional ou missão internacional para as situações de expatriação demandada e gerida pela organização (Adler \& Gundersen, 2008; Freitas, 2002; Cerdin, 2002).

O processo de expatriação, segundo Bueno (2004, p. 1), é o "conjunto de atividades que vai desde o recrutamento e seleção [...] até o acompanhamento do indivíduo no novo ambiente 
organizacional". Tanure, Evans e Pucik (2007) reconhecem que a expatriação é um processo, desde a seleção até a repatriação. De acordo esses mesmos autores, o processo de expatriação possui 8 etapas, conforme apresentado na Figura 1.

Figura 1 - Etapas do processo de expatriação

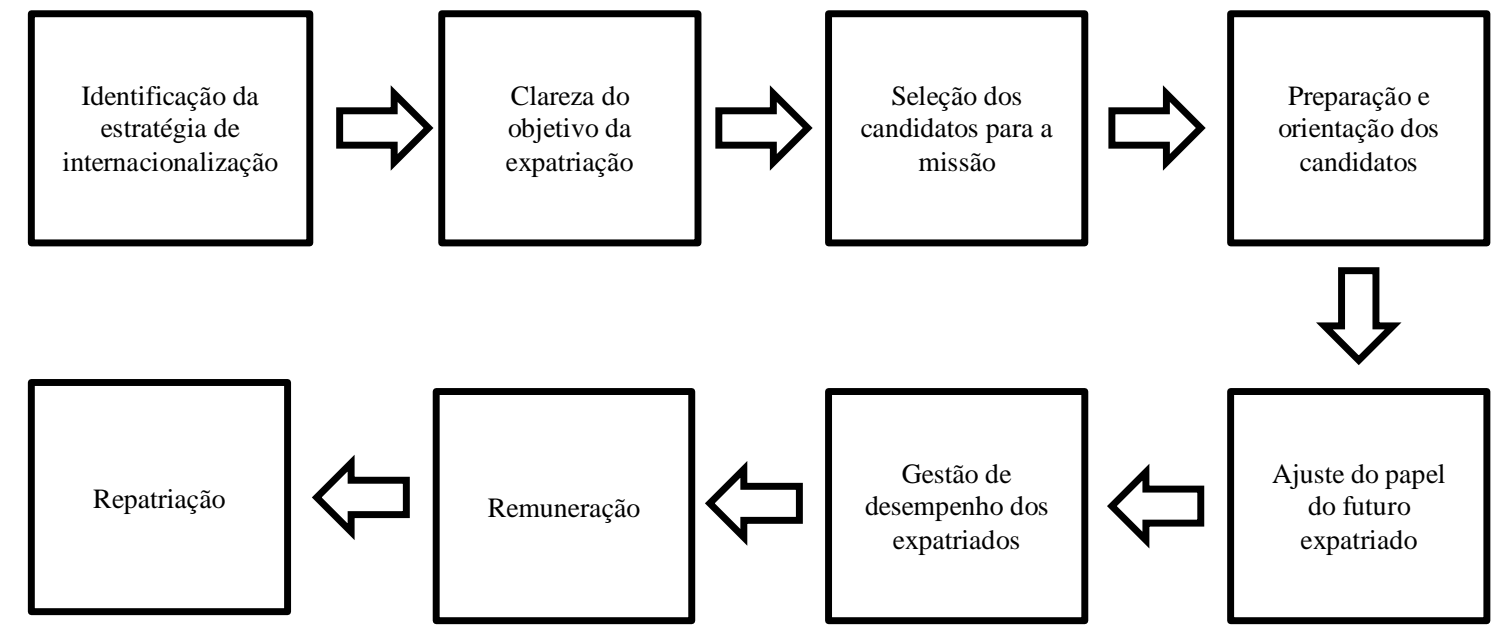

Fonte: Adaptado de Tanure, Evans e Pucik (2007).

Para Black e Mendenhall (1991), durante esse processo de expatriação o expatriado passa por fases de adaptação, a saber: a lua-de-mel, o choque cultural, a adaptação e a maturidade. Na primeira, notam-se comportamentos de excitação e encantamento pelo que vê. A segunda fase é a de decepção e frustração. Na terceira, acontece a adaptação, de forma gradual, à nova cultura. Na última, o indivíduo age com eficiência diante da nova cultura.

No que tange ao período da duração da missão internacional, Rego e Cunha (2009) descrevem três tipos de mobilidade: missões de curta duração (até seis meses); missões de longa duração (entre seis meses e três-cinco anos); e os "expatriados" permanentes.

Em relação aos tipos de expatriados, alguns autores identificaram a necessidade de diferenciá-los em organizacionais [EOs] e voluntários [EVs] (Suutari \& Brewster, 2000). Os primeiros são os profissionais enviados ao exterior para ocuparem um cargo específico ou para 
Mobilidade internacional profissional: uma revisão bibliométrica

atuarem na realização de uma meta (Peltokorpi \& Froese, 2009). Já os últimos trabalham no exterior com vínculo empregatício por iniciativa própria.

A área de Recursos Humanos tem importância estratégica na internacionalização das organizações e no processo de mobilidade internacional, daí surgiu um novo campo de atuação: a área de Gestão de Recursos Humanos Internacional [GRHI], na qual surgem políticas e práticas que objetivam o gerenciamento dos expatriados, que colaboram para a permuta de conhecimento entre as demais filias e para o desenvolvimento dos negócios (Caligiuri, 2000; Gallon, Scheffer \& Bitencourt, 2014; Homem \& Tolfo, 2004). Para Domingues (2011), o desenvolvimento do profissional que trabalhará como gestor internacional e o pensamento da carreira como um todo são importantes, pois por meio de um trabalho integrado e de interesse do indivíduo, haverá o planejamento da carreira que é visto como o principal aspecto das formações de trabalho.

\section{Procedimentos Metodológicos}

Este trabalho apresenta uma análise bibliométrica de publicações entre os anos 2000 e 2017. Sendo que a escolha do período foi definida após um levantamento sobre as publicações, sem a determinação de um período específico de tempo, a priori, e os achados mais significativos e consistentes sobre o tema mobilidade internacional profissional foram encontrados a partir do ano de 2000. Assim sendo, é uma pesquisa de caráter exploratório e, do ponto de vista da abordagem do problema, o estudo pode ser classificado em quantitativo, uma vez que se propõe a quantificar os achados com o uso de técnicas estatísticas e matemáticas (Silva \& Menezes, 2005; Santos, 2007).

Dado o aumento considerável de publicações em revistas científicas, surge a preocupação de analisar o desenvolvimento da produção em determinado campo do saber. Essa avaliação é desejável por validar a confirmação, ou não, do desenvolvimento do estudo e apontar uma direção para sua continuidade, hierarquizar a alocação de recursos humanos e materiais e diagnosticar os potenciais de grupos e/ou instituiçõos específicas (Oliveira, Doréa \& Domene, 1992; Marcelo \& Hayashi, 2013). Para desenvolver esta revisão bibliométrica, foram utilizadas como referência as três leis específicas da bibliometria: de Lotka, de Bradford e de Zipf (Vanti, 2002; Araújo, 2006). 
A Lei de Lotka afirma que a maior parte da literatura científica sobre um tema é produzida por um pequeno número de autores e, no entanto, muitos autores pesquisam pouco sobre o assunto; a lei de Bradford mensura o núcleo e a dispersão do conhecimento científico em um conjunto de periódicos acadêmicos e a Lei Zipf afirma que há uma economia no uso de palavras com a tendência de pouca dispersão, ou seja, poucas palavras vão ser usadas muitas vezes e ajudam a circunscrever um tema.

Também foram monitoradas as redes de coautoria, que nada mais são do que compreender as ligações e as conexões entre autores e suas respectivas Instituições de Ensino Superior [IES] para incentivar o estudo criando parcerias e publicações conjuntas (Ramos-Rodríguez \& Ruíz Navarro, 2004 apud Ribeiro \& Corrêa, 2014).

Depois de realizada uma pesquisa de levantamento preliminar para definição do período a ser pesquisado (2000 a 2017), utilizou-se como ferramentas de busca o Portal de Periódicos da Capes e a biblioteca eletrônica SPELL, nas quais foram encontrados 53 artigos relacionados ao tema mobilidade internacional profissional. Nessa etapa, empregou-se as seguintes palavraschaves: carreira internacional, expatriação, internacionalização, mobilidade, Recursos Humanos e mobilidade internacional. Para filtrar as informações coletadas, aplicou-se alguns critérios, a saber: artigos em português, entre os anos 2000 e 2017, uso das aspas e junção de duas ou mais palavras.

A partir da identificação dos artigos a serem analisados foi criada uma planilha eletrônica, na qual foram classificadas e analisadas informações como: ano de publicação, periódico, título, autores, resumo, palavras-chaves, abordagens, tipos de pesquisa, objetivos, procedimentos de coletas de dados, técnicas de análise, obras utilizadas e citações. A partir daí foi possível a elaboração de gráficos, tabelas e figuras, que serão apresentadas na próxima seção.

\section{Apresentação e Análise dos Dados}

Com base na análise da Figura 2, observa-se que os achados se iniciam a partir de 2002 e que se mantêm relativamente constantes até o ano de 2010. Em seguida, há um salto no número de publicações de 2011 em diante, com a concentração em torno de 80\% dos artigos só nesse período. 
Pela linha de crescimento exponencial de publicações, nota-se a importância dada ao tema nos últimos seis anos e a tendência de ela crescer nos próximos.

Figura 2 - Quantidade de publicações ao longo dos anos

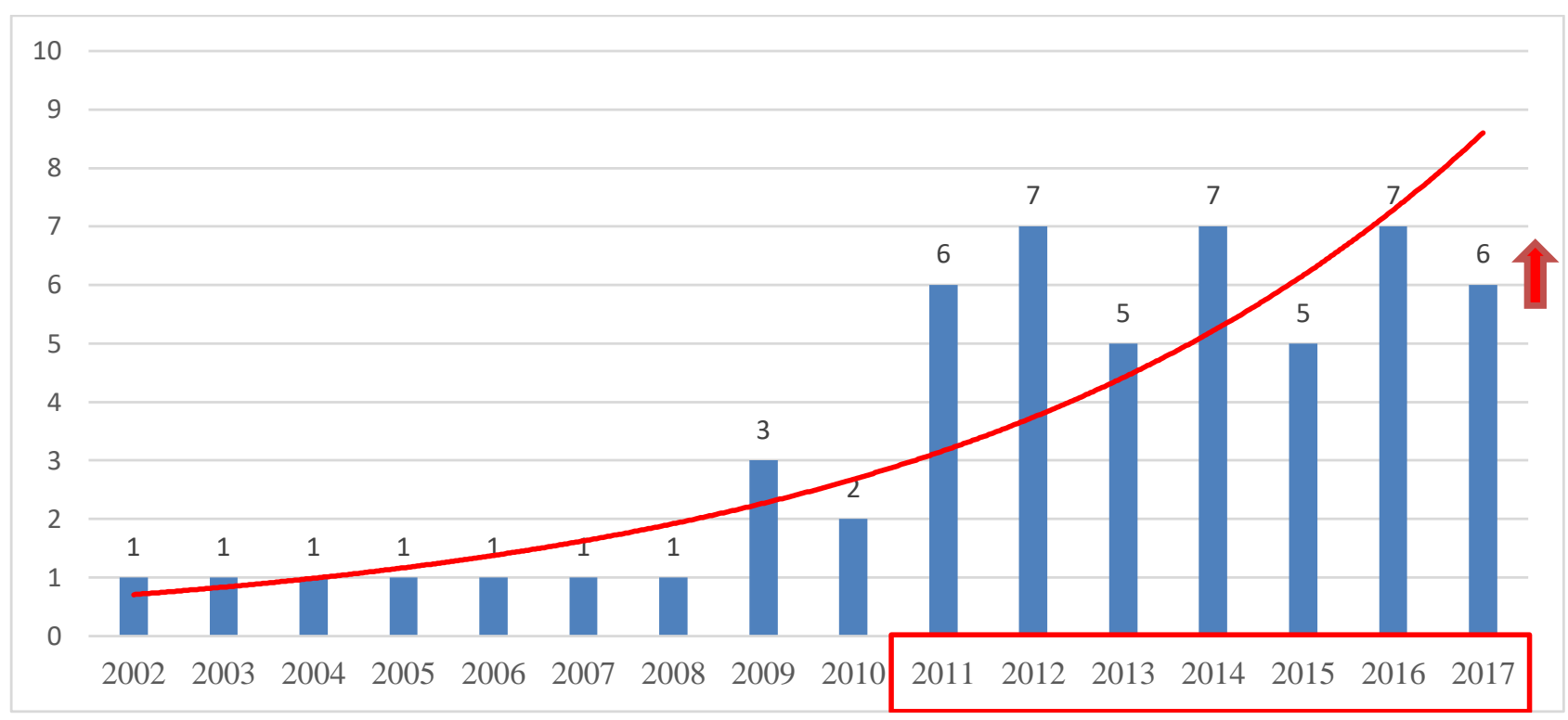

Fonte: Elaborado pelos autores com base nos dados da pesquisa.

Entre as publicações percebe-se que $87 \%$ dos trabalhos foram feitos em conjunto. A formação em dupla se sobressai, com $40 \%$ das publicações, seguida das produções com três autores, $32 \%$, de 2014 em diante, sendo todos os estudos em parceria.

Também a Figura 3 evidencia que a autora Shalimar Gallon foi a que mais publicou nesse período, com $20 \%$ de participação. Em seguida, com cinco artigos, está Ângela Beatriz Busato Scheffer e Betina Magalhães Bitencourt. Na sequência, cada qual com três publicações, surgem os autores Edson Keyso de Miranda Kubo e Maria Ester de Freitas. No somatório total, os autores contribuíram com $28 \%$ dos artigos contra discrepância no número de autores que escreveram apenas uma publicação. Do total de 96 nomes, 88\% deles se enquadram nessa realidade, o que demonstra que muitos pesquisadores publicam pouco e poucos autores publicam muito sobre assuntos numa área de conhecimento, confirmando a Lei de Lotka. 
Figura 3 - Autores mais frequentes

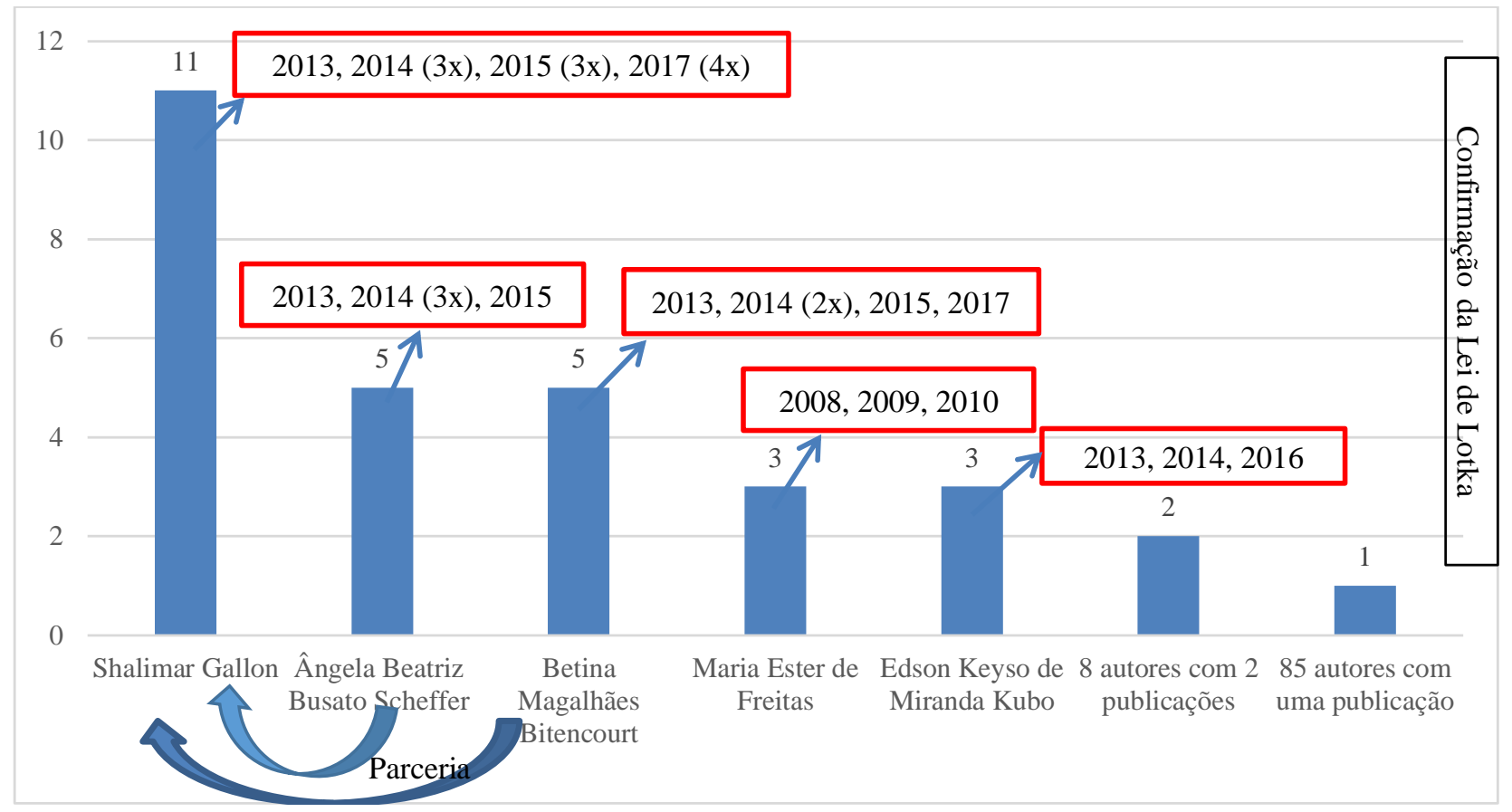

Fonte: Elaborado pelos autores com base nos dados da pesquisa.

Os autores mais recorrentes demonstram o quanto o tema está sendo alvo de estudos, de 2013 até 2017. Somente Shalimar teve seis trabalhos aprovados entre os anos 2014 e 2015. Ela sempre publicou em parceria com outros autores, tais como Ângela Beatriz Busato Scheffer e Betina Magalhães Bitencourt que, nas obras encontradas, sempre publicaram em conjunto com a primeira.

Conforme os dados, os três autores que mais publicaram estão seguindo a linha focada na Gestão de Pessoas: suas políticas, modelos e práticas, logo, não são tão específicos. Já as autoras Shalimar e Ângela são bem mais diretas, posicionando o tema como: Mobilidade Internacional expatriação. Como se sabe, há outras linhas de pesquisa como internacionalização, repatriação, gestão de pessoas internacional e recursos humanos internacionais. No entanto, ao analisar as publicações, percebe-se que a grande área de pesquisa é os Estudos Organizacionais, tendo Recursos Humanos com expressivo número de abordagens, seguida da Sociologia e da Estratégia. 
Assim sendo, a ampliação das pesquisas por meio de um olhar de outras áreas demonstra que o campo é mais amplo e vai além.

A Figura 4, apresenta as referências de autores em diversos idiomas que trabalham o tema. O autor que obteve mais citações foi J. Stewart Black, com 84 citações, presente em 44\% dos artigos, seguido por Rosalie L. Tung, que aparece com 76 citações, em 18 artigos. A brasileira com maior citação é Maria Ester de Freitas, em 23 artigos, superando os dois primeiros nesse quesito. Tem-se adiante Mark E. Mendenhall, que costuma trabalhar em parceria com o primeiro colocado e com Hal B. Gregersen e Gary Oddou em vários artigos. Porém, esses autores fazem parte de apenas 36\% das 1435 citações tabuladas.

\section{Figura 4 - Autores mais citados}

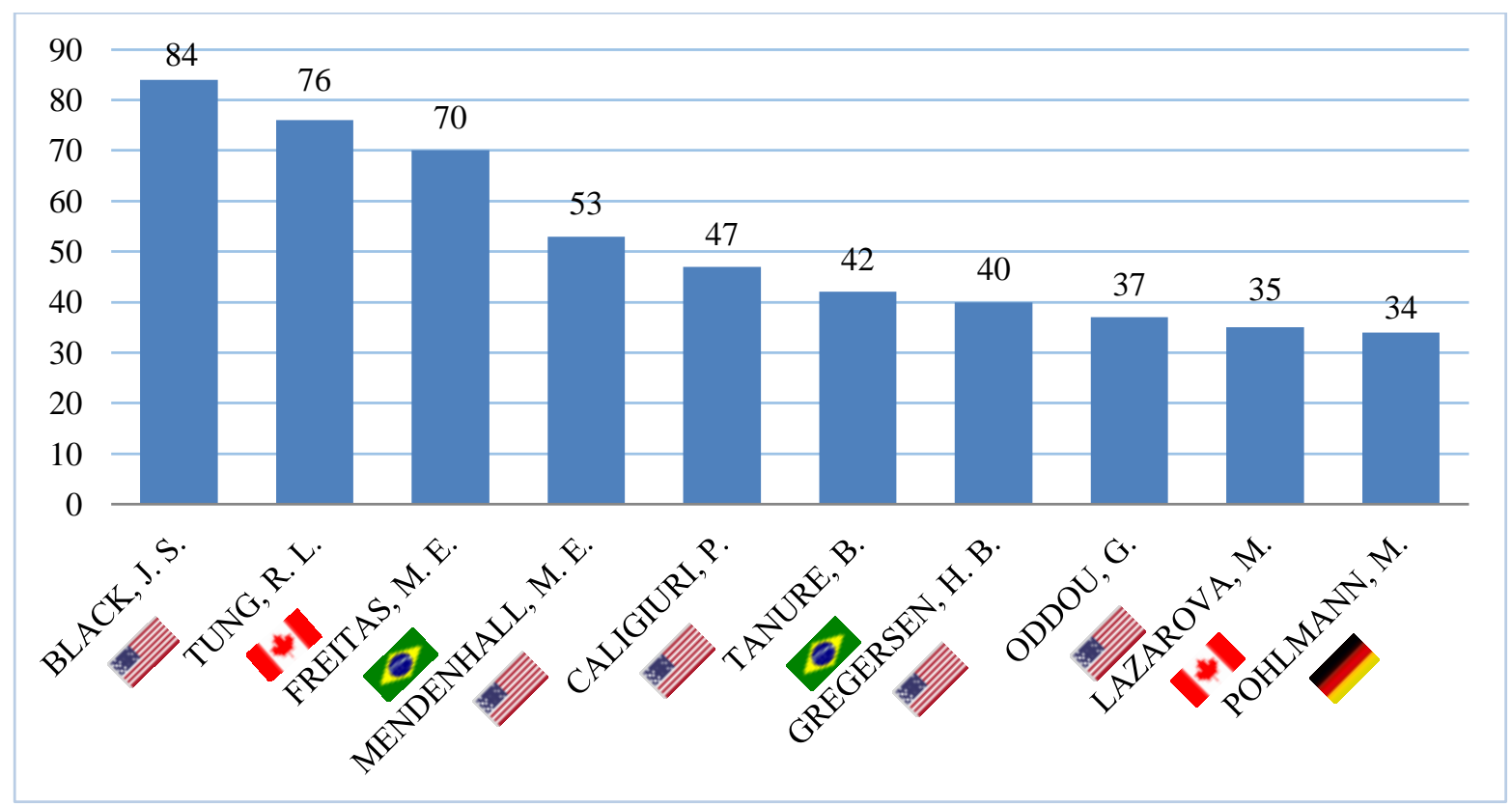

Fonte: Elaborado pelos autores com base nos dados da pesquisa.

Pesquisando o perfil dos autores, percebe-se que 50\% deles são dos Estados Unidos, dois são canadenses, duas são brasileiras e um é alemão. Pode-se inferir que o tema, além de ser abordado em diversos países, tem servido de foco para outros intelectuais produzirem seus artigos em outras partes do mundo. 
A obra mais utilizada é o livro "A gestão de pessoas no Brasil”, que aparece em 11 artigos e em 33 citações. Isso demonstra o quanto o tema está atrelado aos Recursos Humanos. Em seguida, está o livro de Andrés Solimano, que foi citado em 32 ocasiões, porém somente em um artigo. Rosalie L. Tung e Maria Ester de Freitas surgem com dois trabalhos cada uma, que vão ao encontro da linha de atuação dessas autoras. A maioria das obras utilizadas é internacional, somente duas são nacionais. As citações estão em 66\% dos artigos e aparecem 229 vezes. Por fim, observa-se que há trabalhos antigos (1988) e recentes (2009) que inspiram as produções, logo esse tema já é objeto de discussão há algum tempo.

A pesquisa identificou que os estudos estavam concentrados em 40 instituições; os vinculados à Universidade Federal do Rio Grande do Sul [UFRGS] totalizam 22 participações, em 11 artigos e, em 7 deles, há somente pesquisadores ligados a essa instituição. Em seguida, aparecem a Universidade Federal de Santa Maria [UFSM], com 10 colaborações; a Universidade Municipal de São Caetano do Sul [USCS], com 9; a Fundação Getúlio Vargas [FGV], com 8; a Mackenzie e Universidade Estadual de Maringá [UEM], com 5; a Universidade Federal Fluminense [UFF] e a Universidade Federal de Viçosa [UFV], com 4; e a Faculdade Meridional, com 3. Com esta análise foi possível observar a hegemonia de instituições de ensino superior da região sul e sudeste na participação referente ao tema.

Outra análise interessante diz respeito ao índice de ligação, isto é, na ocorrência de coautorias. Existem 26 artigos feitos exclusivamente por autores de uma mesma instituição, já em 18 publicações houve colaboração entre intelectuais de universidades diferentes e 8 foram feitos individualmente. Esse dado mostra que, em $85 \%$ deles houve interesse pela cooperação em pesquisas e, em 34\%, houve coautoria entre autores de mais de uma instituição, fator importante para troca de conhecimento e disseminação do assunto. Vale salientar que 3 artigos foram produzidos por autores vinculados a universidades estrangeiras (Universidade de Heidelberg, Instituto Universitário de Lisboa e Universidade do Minho) e publicados em periódicos nacionais.

Do ponto de vista da abordagem de pesquisa, percebeu-se que $87 \%$ dos artigos levantados possuem uma abordagem qualitativa, já que houve a busca por perceber e entender a natureza geral da questão e, a partir daí, abriu-se espaço para interpretação. A maior parte dos estudos possui caráter exploratório, cerca de $70 \%$, estimulando os entrevistados, via roteiros semiestruturados, a 
pensarem de maneira livre sobre o tema e suas ramificações, mostrando aspectos subjetivos que atingiram motivações que não estavam explícitas ou conscientes, de forma espontânea. Houve uma relativa constância desse caráter durante os anos, mas uma frequência maior nos últimos sete. Os estudos somente descritivos começam a surgir a partir de 2009 e fazem parte da formação de 9 artigos. Já os descritivos-exploratórios e os descritivos-analíticos estão em 4 artigos cada um. Logo, conclui-se que os investigadores estão ansiosos por descrever as características da população de expatriados ou por estabelecer relações entre variáveis. Outro destaque vai para os analíticos, uma vez que a partir de 2010 o que já é sabido sobre o assunto necessita de uma explicação. Em relação os procedimentos técnicos, o estudo de caso foi o mais evidente, embora, além dele, tenha havido estudo bibliográfico e documental.

\section{Figura 5 - Periódicos mais frequentes}

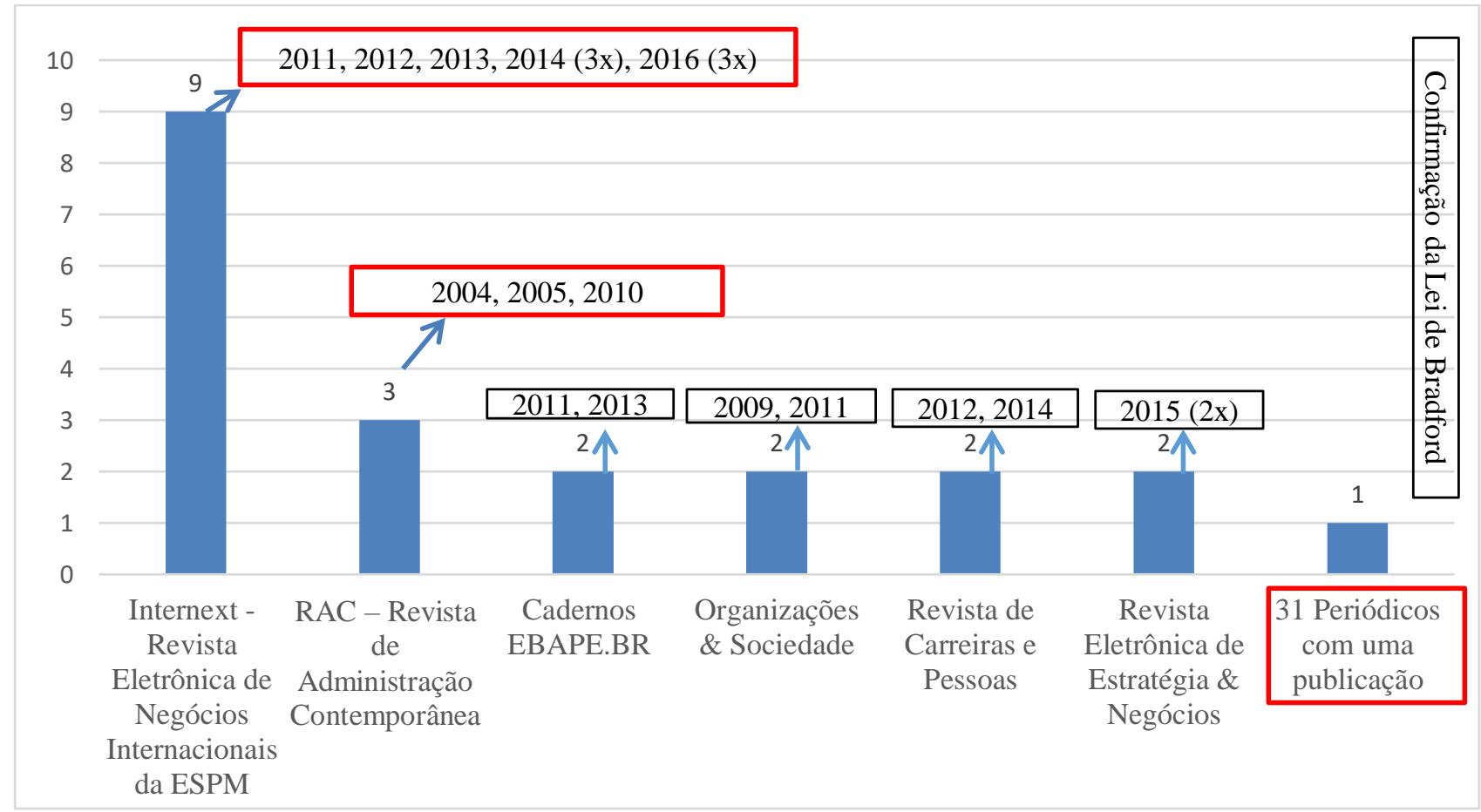

Fonte: Elaborado pelos autores com base nos dados da pesquisa.

Ao visualizar a Figura 5, observa-se que os artigos foram distribuídos em 37 periódicos, contudo, a InternexT - Revista Eletrônica de Negócios Internacionais da ESPM foi a que mais publicou sobre o assunto nos últimos 6 anos, no total de 9 artigos. $O$ tema converge com a proposta 
da revista de ser um veículo acadêmico para produções na área de Gestão Internacional. Em seguida, está a Revista de Administração Contemporânea [RAC], com 3 artigos, os Cadernos EBAPE.BR, com 2, ambos focados em contribuir na Administração em geral. A revista Organizações \& Sociedade, que focaliza a área de Estudos Organizacionais, teve 2 publicações, juntamente com a Revista de Carreiras e Pessoas, que possui como um dos seus focos de interesse a Gestão de Pessoas, e a Revista Eletrônica de Estratégia \& Negócios, está mais voltada para os temas de estratégia e gestão em geral. Por meio desses dados, obtém-se a confirmação da Lei de Bradford, de que poucos periódicos produzem muitos artigos e muitos periódicos produzem poucos artigos. Tal fato é relevante para mostrar a concentração do tema em certos periódicos específicos, o que facilita tanto no momento de pesquisa sobre o assunto como no processo de definição de onde endereçar suas publicações.

\section{Figura 6 - Frequência de Palavras-Chave}
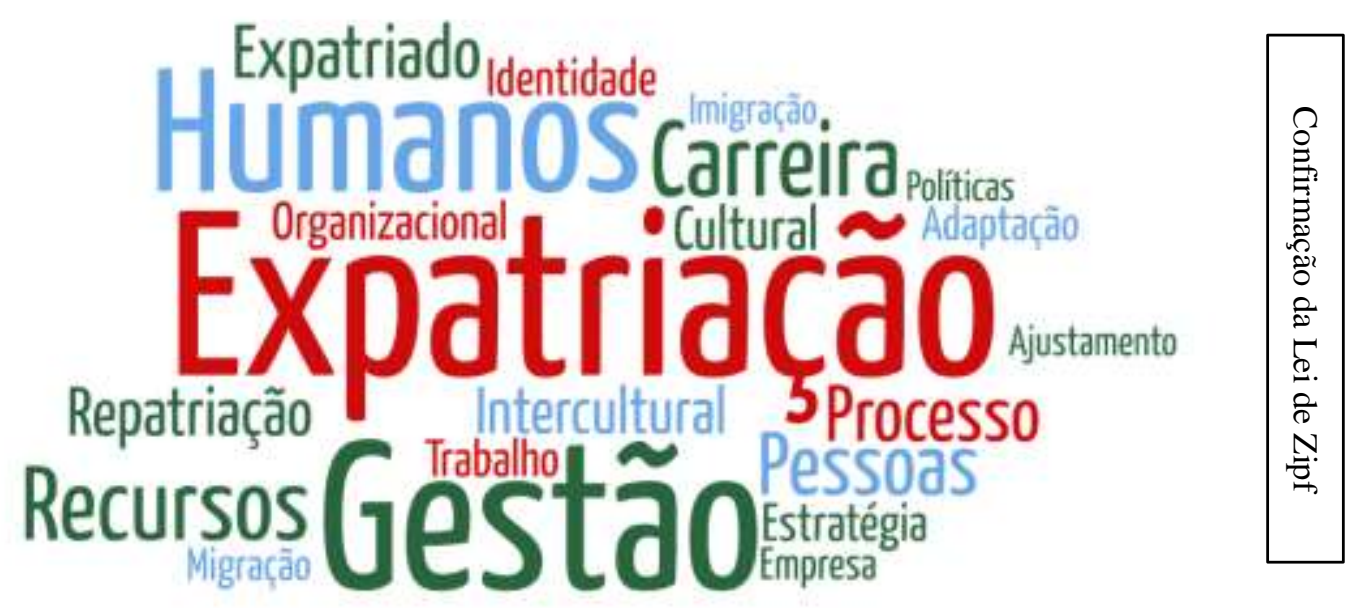

Fonte: Elaborado pelos autores com base nos dados da pesquisa.

Ao utilizar a ferramenta Tagul, (software que permite, a partir de um agrupamento de palavras, a criação de nuvens de palavras) foi criada a Figura 6 advinda das palavras-chave utilizadas nos artigos encontrados. É possível notar que os termos expatriação, gestão, recursos, humanos, carreira e pessoas são os mais expressivos. Contíguo está a palavra estratégia, para mostrar que a mobilidade internacional é mais um meio das empresas atingirem maiores resultados. 
Mobilidade internacional profissional: uma revisão bibliométrica

Por meio da Figura 7, observa-se uma linha cronológica dos objetivos gerais suscitados pelos autores de cada artigo. A partir delas, tem-se uma visão geral da trajetória do tema e seus subtemas ao longo do período analisado:

Figura 7 - Objetivos gerais por ano de publicação

\begin{tabular}{|c|c|c|}
\hline 2002 & 2004 & 2005 \\
\hline $\begin{array}{l}\text { • Estimar a intensidade, a } \\
\text { origem, o destino, as motivações } \\
\text { gerais e os padrões de retorno dos } \\
\text { deslocamentos de pesquisadores } \\
\text { brasileiros durante parte da década } \\
\text { de } 1990 .\end{array}$ & $\begin{array}{l}\text { • Investigar o processo de } \\
\text { alteridade em expatriados e suas } \\
\text { implicações nas situações de trabalho }\end{array}$ & $\begin{array}{l}\text { - Discutir o papel que a } \\
\text { família do expatriado exerce no } \\
\text { processo de seu ajustamento cultural }\end{array}$ \\
\hline 2006 & 2008 & 2009 \\
\hline $\begin{array}{l}\text { • Estabelecer relações entre as } \\
\text { novas formas organizacionais e as } \\
\text { mudanças que vêm ocorrendo, em } \\
\text { especial, na questão dos executivos } \\
\text { "sem fronteiras". } \\
\text { • Caracterizar as novas formas } \\
\text { organizacionais e desvendar os } \\
\text { paradoxos existentes nas relações } \\
\text { entre expatriados e organizações. }\end{array}$ & $\begin{array}{l}\text { • Verificar quais os fatores } \\
\text { relacionados às políticas de gestão de } \\
\text { pessoas (compensação e seleção) de } \\
\text { uma organização que contribuem } \\
\text { para o sucesso da atribuição } \\
\text { internacional. }\end{array}$ & $\begin{array}{l}\text { - Analisar a mobilidade como } \\
\text { um novo capital simbólico no mundo } \\
\text { organizacional. } \\
\text { • Apreender as } \\
\text { transformações identitárias dos } \\
\text { expatriados. Descrever as } \\
\text { experiências de indivíduos durante o } \\
\text { processo de expatriação e retorno ao } \\
\text { Brasil. } \\
\text { • Analisar aspectos que } \\
\text { favorecem ou dificultam processos } \\
\text { de expatriação e repatriação, } \\
\text { vivenciados por profissionais de } \\
\text { organizações brasileiras. }\end{array}$ \\
\hline 2010 & 2011 & 2012 \\
\hline $\begin{array}{l}\text { - Apresentar a avaliação das } \\
\text { expatriações feita pelos entrevistados } \\
\text { e suas sugestões para que as } \\
\text { empresas aperfeiçoem seus } \\
\text { processos, tornando-os mais } \\
\text { humanos e responsáveis. } \\
\text { - Analisar as sugestões para } \\
\text { as empresas melhorarem os seus } \\
\text { processos de expatriação. Sugerir } \\
\text { cuidados aos profissionais que } \\
\text { pretendem se expatriar. }\end{array}$ & $\begin{array}{l}\text { • Levantar e analisar as } \\
\text { políticas e práticas de Recursos } \\
\text { Humanos adotadas por empresas } \\
\text { brasileiras internacionalizadas e } \\
\text { multinacionais estrangeiras } \\
\text { estabelecidas no Brasil no processo } \\
\text { de repatriação de executivos } \\
\text { brasileiros expatriados. } \\
\text { • Explorar quais e como as } \\
\text { narrativas estão presentes na vida dos } \\
\text { gerentes expatriados. } \\
\text { • Discutir o desenvolvimento } \\
\text { de pessoas para uma gestão } \\
\text { estratégica na internacionalização } \\
\text { identificando os gaps existentes e } \\
\text { trazendo recomendações para as } \\
\text { empresas brasileiras. } \\
\text { • Examinar se as abordagens } \\
\text { desenvolvidas por pesquisas que } \\
\text { analisam a expatriação de } \\
\text { profissionais de multinacionais de }\end{array}$ & $\begin{array}{l}\text { • Discutir a efetividade da } \\
\text { expatriação como estratégia para } \\
\text { geração de conhecimento } \\
\text { organizacional e crescimento na } \\
\text { carreira, segundo a percepção dos } \\
\text { expatriados. } \\
\text { • Analisar questões que } \\
\text { envolvem a gestão intercultural nas } \\
\text { organizações e demonstrar que a } \\
\text { interculturalidade é uma das } \\
\text { consequências da mobilidade de } \\
\text { profissionais. } \\
\text { • Diferenciar expatriados } \\
\text { voluntários e organizacionais no } \\
\text { Brasil. } \quad \text { Debater os principais } \\
\text { • } \quad \text { argumentos das abordagens sobre a } \\
\text { mobilidade e contribuir na } \\
\text { consolidação de ideias sobre as } \\
\text { melhores práticas políticas na gestão }\end{array}$ \\
\hline
\end{tabular}




\begin{tabular}{|c|c|c|}
\hline & $\begin{array}{l}\text { países desenvolvidos para suas filiais } \\
\text { em países emergentes ajudam a } \\
\text { entender essa experiência. } \\
\text { - Analisar o processo de } \\
\text { expatriação da WEG Equipamentos } \\
\text { Elétricos S.A na China. } \\
\text { - Identificar, nos relatos dos } \\
\text { expatriados, a ocorrência de } \\
\text { transformações na identidade dos } \\
\text { sujeitos e identificar, nas } \\
\text { experiências dos entrevistados, a } \\
\text { ocorrência de padrões de adaptação à } \\
\text { cultura de destino. }\end{array}$ & $\begin{array}{l}\text { de competências no espaço nacional } \\
\text { e global. } \\
\text { - Avaliar como ocorreu o } \\
\text { processo de ajustamento } \\
\text { internacional de expatriados } \\
\text { brasileiros na China e na Espanha. } \\
\text { - Descrever cinco indicadores } \\
\text { psicossociais de saúde positiva de } \\
\text { empregados expatriados. } \\
\text { - Realizar um estudo } \\
\text { bibliométrico, analisando a produção } \\
\text { científica sobre o tema expatriados, } \\
\text { ao longo do período de } 2000 \text { a } 2012 \text {. }\end{array}$ \\
\hline 2013 & 2014 & 2015 \\
\hline $\begin{array}{l}\text { - Analisar a relação percebida } \\
\text { entre repatriação e expectativas de } \\
\text { carreira profissional por parte dos } \\
\text { profissionais que tiveram ou estão } \\
\text { tendo uma experiência internacional. } \\
\text { • Analisar o ajustamento } \\
\text { intercultural de executivos japoneses } \\
\text { expatriados. } \\
\text { • Refletir sobre o gênero } \\
\text { como elemento que estrutura o fluxo } \\
\text { internacional de pessoas. } \\
\text { • Examinar a hipótese da } \\
\text { internacionalização da alta gerência } \\
\text { industrial brasileira por meio do grau } \\
\text { de internacionalização de sua } \\
\text { carreira no contexto da globalização. } \\
\text { • Apresentar um estudo de } \\
\text { caso de uma empresa de engenharia } \\
\text { e construção brasileira globalizada. }\end{array}$ & $\begin{array}{l}\text { • Discutir o papel estratégico } \\
\text { do processo de expatriação na } \\
\text { internacionalização da empresa. } \\
\text { • Identificar a percepção do } \\
\text { expatriado brasileiro em relação à } \\
\text { distância psíquica na } \\
\text { internacionalização. } \\
\text { • Explorar as motivações dos } \\
\text { franceses que buscam a EIA no } \\
\text { Brasil. } \\
\text { • Analisar as estratégias } \\
\text { relacionadas aos fatores intrínsecos e } \\
\text { extrínsecos da decisão de } \\
\text { expatriação. } \\
\text { • Analisar a estratégia de } \\
\text { expatriação no âmbito do expatriado, } \\
\text { da empresa multinacional e do } \\
\text { ambiente internacional. } \\
\text { • Analisar o processo de } \\
\text { repatriação e as expectativas dos } \\
\text { empregados repatriados e identificar } \\
\text { os desafios para as organizações. } \\
\text { • Analisar o programa trainee } \\
\text { e o processo de expatriação para } \\
\text { entender como esses influenciaram } \\
\text { na carreira dos entrevistados. }\end{array}$ & $\begin{array}{l}\text { • Analisar a percepção dos } \\
\text { empregados que tiveram/estão tendo } \\
\text { uma experiência internacional sobre } \\
\text { o impacto em suas carreiras. } \\
\text { • Verificar e conhecer a } \\
\text { atuação do profissional de } \\
\text { Secretariado Executivo no processo } \\
\text { de adaptação de executivos } \\
\text { expatriados no Brasil, mapeando as } \\
\text { atividades, os desafios e } \\
\text { competências necessárias. } \\
\text { - Analisar as fases da } \\
\text { expatriação a fim de mapear um } \\
\text { modelo compatível com as } \\
\text { estratégias internacionais da } \\
\text { organização. } \\
\text { • Analisar os fatores } \\
\text { relevantes para a permanência dos } \\
\text { repatriados nas organizações. } \\
\text { • Analisar os programas } \\
\text { trainee e o processo de expatriação } \\
\text { para mostrar a relevância estratégica } \\
\text { da Gestão de Recursos Humanos. }\end{array}$ \\
\hline 2016 & 2017 & \\
\hline $\begin{array}{l}\text { - Analisar as expectativas e as } \\
\text { percepções dos repatriados sobre o } \\
\text { crescimento na carreira e o } \\
\text { reconhecimento. } \\
\text { • Descrever e compreender as } \\
\text { vivências e as experiências dos } \\
\text { expatriados. }\end{array}$ & $\begin{array}{l}\text { • Analisar o comportamento } \\
\text { resiliente de brasileiros expatriados } \\
\text { na China diante da experiência de } \\
\text { expatriação. } \\
\text { - Sendo a expatriação um } \\
\text { contexto de integração social, } \\
\text { analisar a dificuldade do momento } \\
\text { do regresso do expatriado nos }\end{array}$ & \\
\hline
\end{tabular}


Mobilidade internacional profissional: uma revisão bibliométrica

\begin{tabular}{|c|c|}
\hline $\begin{array}{l}\text { • Discutir como a } \\
\text { globalização aumentou a mobilidade } \\
\text { internacional de médicos. Traçar um } \\
\text { panorama dos principais movimentos } \\
\text { migratórios atuais de médicos. } \\
\text { - Analisar a relação entre o } \\
\text { desenvolvimento da economia } \\
\text { capitalista e a mobilidade } \\
\text { internacional da força de trabalho. } \\
\text { - Comparar as políticas de } \\
\text { recrutamento e seleção nos } \\
\text { programas de expatriação das } \\
\text { empresas brasileiras. } \\
\text { - Caracterizar a percepção de } \\
\text { profissionais brasileiros expatriados } \\
\text { para a Índia e a China sobre a sua } \\
\text { qualidade de vida no trabalho. } \\
\text { - Apresentar o resultado de } \\
\text { um estudo bibliométrico a respeito } \\
\text { de empreendedorismo imigrante e de } \\
\text { enclaves étnicos. Identificar lacunas } \\
\text { da literatura brasileira e } \\
\text { internacional. }\end{array}$ & $\begin{array}{l}\text { quadros de socialização e de ação } \\
\text { (re)constituídos por práticas } \\
\text { organizacionais de expatriação. } \\
\bullet \quad \text { Analisar os conceitos e } \\
\text { configurações que os expatriados } \\
\text { assumem conforme ocorre a } \\
\text { internacionalização das empresas. } \\
\text { • Analisar as configurações da } \\
\text { Gestão de Recursos Humanos das } \\
\text { empresas portuguesas e brasileiras } \\
\text { no que concerne aos negócios } \\
\text { internacionais. } \\
\text { • Analisar as políticas e } \\
\text { práticas de Gestão de Pessoas do } \\
\text { processo de expatriação. } \\
\text { • Analisar as configurações da } \\
\text { GP a fim de atender as estratégias da } \\
\text { organização e gerir o processo de } \\
\text { expatriação no que concerne aos } \\
\text { negócios internacionais. }\end{array}$ \\
\hline
\end{tabular}

Fonte: Elaborado pelos autores com base nos dados da pesquisa.

Foi possível analisar a evolução dos temas e contribuições ao longo do tempo sendo que, entre 2002 e 2005, o foco das poucas publicações deste período estava no indivíduo relacionandoo com suas motivações para a mobilidade internacional, o processo de reconhecimento de si mesmo e do outro e o papel da família. Este período coincide com o aumento do processo de internacionalização de empresas brasileiras e da vinda de muitas empresas estrangeiras para o Brasil, estimuladas pela intensificação da globalização de mercados auxiliada pelo uso de tecnologia de informação e comunicação. Isto pode explicar, pelo menos em parte, o porquê de alguns pesquisadores terem começado a se interessar pelo tema.

No período de 2006 a 2009, o foco das pesquisas esteve voltado para a relação indivíduoorganização em diferentes perspectivas como: carreira, transformações identitárias, políticas de gestão da mobilidade internacional, papel e importância da mobilidade internacional para as organizações e desenvolvimento ou etapas do processo.

Já entre 2010 e 2012, foi possível observar que o foco das pesquisas estava na avaliação e sugestões de melhoria dos processos e programas de mobilidade internacional, além da relação 
entre essa e as estratégias de Recursos Humanos e as estratégias organizacionais. Alguns temas são evidenciados como a gestão do conhecimento, a carreira internacional e os problemas com a etapa de repatriação dos profissionais. Importante ressaltar que em 2012 foi a primeira vez que apareceu a preocupação em discutir os diferentes tipos de mobilidade internacional (voluntária e profissional, por exemplo) e também é publicado nesse ano um estudo bibliométrico sobre o tema.

Nos anos de 2013 a 2015, o foco parece voltar para o indivíduo com trabalhos que analisam os problemas com o ajuste cultural, a carreira e a repatriação, na perspectiva do profissional envolvido. Questões de gênero e também sobre a preparação para a mobilidade como os programas de trainnee, além de temas como as decisões para se expatriar e as expectativas do profissional com o processo são objeto de pesquisa nesse período.

Por fim, entre 2016 e 2017, alguns trabalhos focam na avaliação do processo de mobilidade internacional tanto na perspectiva individual quanto organizacional abordando novamente questões como carreira, mas também tratando sobre reconhecimento, o aumento da mobilidade internacional nas empresas, o papel da área de RH e suas contribuições. Um achado interessante é que somente neste período foram identificados estudos comparados entre Brasil e outros países ou entre empresas brasileiras e empresas estrangeiras atuando no Brasil. E também aumenta o interesse em identificar e analisar diferentes tipos e configurações de mobilidade internacional.

Um aspecto importante é a denominação e as funções do setor responsável por esse processo que foi sofrendo alterações ao longo dos anos: chamada de Gestão de Pessoas (2008), Recursos Humanos (2010) e Gestão de Recursos Humanos (2015). O termo área de Recursos Humanos ainda é o mais citado, mas tem se dividido em subáreas para atender aos processos de mobilidade internacional (GRHI e Gestão de Expatriados). O papel desta área tem sido discutido ao longo do período estudado na definição e execução de políticas para a mobilidade internacional, assim como a importância deste processo para a estratégia de internacionalização das empresas. Por meio da análise dos dados coletados, infere-se que a área de Recursos Humanos tem tentado conhecer mais a fundo como a mobilidade internacional pode ser uma estratégia que venha a refletir nos resultados e na melhoria do ambiente interorganizacional.

Houve a realização de estudos bibliométricos relacionados ao tema em 2012 e 2016 para promover a análise bibliográfica, com o intuito de conhecer o tamanho e as características do 
acervo, organizar o que já foi produzido, elaborar previsões de crescimento ou ajudar na solução de lacunas ainda presentes no tema. Este fato reforça a percepção de que houve aumento do interesse pelo tema no Brasil e ajuda na análise da sua evolução e reconhecimento de pesquisadores e periódicos que têm se destacado.

Foi possível observar que, a partir de 2009, começa a surgir a ação de "analisar" e "avaliar" nos propósitos dos autores e elas se tornam mais evidentes a partir de 2013. Porém, apenas quatro artigos definem-se como descritivos e analíticos nesse período. Assim, mesmo envolvendo o aprofundamento do estudo e da avaliação de informações disponíveis na tentativa de explicar o contexto do fenômeno, a maioria das pesquisas desse período intitulam-se exploratórias. Do ponto de vista de paradigmas de pesquisa, a maioria dos artigos analisados apoiou-se (declaradamente ou não) no paradigma funcionalista tendo como unidade de análise a empresa. Mas, também foram encontrados artigos com abordagens mais interpretativistas que privilegiaram a perspectiva do indivíduo.

Apesar do crescimento das publicações ao longo dos anos, comparando-se com o cenário internacional, observa-se que o tema ainda é pouco estudado no Brasil. A critério de comparação, no mesmo período desta pesquisa e usando os mesmos parâmetros na base de dados Web of Science, por exemplo, foram encontrados mais de 5.000 artigos, sendo a maior parte deles de abordagem quantitativa e do tipo estudos comparados (cross-cultural). Uma questão importante nessa discussão é que, além de só terem sido encontrados um pouco mais que cinco dezenas de artigos em um período de 15 anos, vários deles foram derivados de uma mesma pesquisa (partindo de teses ou dissertações).

\section{Considerações Finais}

O interesse pelo tema e a complexidade dos problemas de pesquisa foram aumentando ao longo do tempo analisado demonstrando a sua importância tanto para os profissionais quanto para as empresas e meio acadêmico, apesar da quantidade de artigos publicados ser relativamente baixa comparando-se com bases internacionais. Cabe salientar, também, que algumas pesquisas geraram vários artigos, o que pode explicar o número maior de publicações de alguns autores. 
Como resultado da revisão bibliométrica tem-se que a produção acadêmica está em uma curva ascendente, concentrada em poucos autores, um pequeno número de palavras-chaves é recorrente em todos os trabalhos e um periódico se destaca na publicação, enquanto o restante está pulverizado em um grande número de periódicos. Detalhadamente: com base na lei de Lotka (Figura 3), identificou-se que 5 autores concentraram boa parte da produção científica enquanto 93 pesquisadores publicaram pouco: 85 deles, apenas uma vez. Já pela Lei de Zipf (Figura 6), percebeu-se que poucas palavras são usadas para sintetizar o tema, neste caso: expatriado, gestão, recursos, humanos, carreira e estratégia foram as mais frequentes. Por fim, pela Lei de Bradford (Figura 5), comprovou-se parcialmente haver concentração em poucos periódicos, sendo que a InternexT - Revista Eletrônica de Negócios Internacionais da ESPM foi o que mais publicou, representando quase $20 \%$ do total e os demais artigos foram publicados de forma pulverizada em 36 periódicos nacionais.

Há uma certa recorrência nas questões de interesse relacionadas ao tema, mas foi possível observar uma evolução: inicialmente, houve uma preocupação maior relacionada aos elementos motivadores e do entorno do indivíduo (família, relacionamentos, alteridade), passando pelo interesse no processo, em si, da mobilidade internacional com suas diferentes etapas focando no ambiente organizacional e, mais recentemente, na avaliação da mobilidade internacional e seu papel na estratégia organizacional envolvendo também a área de Recursos Humanos.

Observaram-se lacunas a serem exploradas e discutidas sobre o tema, como: os tipos de mobilidade internacional (profissional, voluntário, flexpatriado, etc.) e seus diferentes tipos de contratos; as configurações organizacionais para gestão da mobilidade internacional envolvendo a área de Recursos Humanos (GRHI, gestão de expatriados) e suas atribuições; a caracterização da mobilidade internacional em empresas brasileiras; as características e desafios do professional brasileiro para a mobilidade internacional; e o alinhamento entre o processo de mobilidade internacional e a estratégia organizacional são alguns dos temas que parecem promissores e podem contribuir para a construção do conhecimento acadêmico e de gestão no contexto brasileiro.

Como limitação, ressalta-se que os artigos selecionados atenderam a determinados critérios (como a seleção por algumas palavras-chaves específicas) que mostraram um panorama da 
produção acadêmica, isso não significa que não possa haver outros trabalhos relevantes que também podem contribuir para o conhecimento sobre o tema.

\section{Referências}

Adler, N., \& Gundersen, L. (2008). International dimensions of organizational behavior. 4 ed. Cincinnati: South- Western College Publishing.

Araújo, C. A. (2006). Bibliometria: evolução história e questões atuais. Revista em Questão, 12(1), 11-32, jan/jun.

Beck, U. (1999). O que é globalização? Tradução de André Caron. São Paulo: Paz e Terra.

Black, J. S. \& Mendenhall, M. (1991). The U-Curve adjustment hypothesis revisited: A review and theoretical framework. Journal of International Business Studies, 22(2), 225-247.

Bueno, J. M. (2004). O Processo de expatriação como instrumento de integração de culturas em uma organização no Brasil: o caso Renault. Dissertação (Mestrado em Administração) Pontifícia Universidade Católica do Paraná, Curitiba.

Bueno, J. M. (2010). Brasileiros e estrangeiros na construção de um cotidiano organizacional intercultural. Tese (Doutorado). Fundação Getúlio Vargas, São Paulo.

Bueno, J. M., \& Freitas, M. E. (2015). As equipes multiculturais em subsidiárias brasileiras de multinacionais: um estudo de casos múltiplos. Revista Organizações \& Sociedade, 22(72), $15-34$.

Caligiuri, P. M. (2000). Selecting expatriates for personality characteristics: a moderating effect of personality on the relationship between host national contact and cross-cultural adjustment. Management International Review, 40(1), 61-80.

Cerdin, J. L. (2002). L'expatriation. (10a ed.). Paris: Éditions d'Organisation.

Domingues, C. R. (2011). Políticas de carreiras para o gestor internacional: um estudo em empresas brasileiras internacionalizadas. Tese (Doutorado). Fundação Getúlio Vargas. São Paulo. 
Domingues, C. R., \& Bueno, J. M. (2008). Gestão internacional e cultura nacional brasileira: retratos das abordagens e pontos de contato. REBRAE - Revista Brasileira de Estratégia (Impresso), 1(1), 5-20.

Freitas, M. E. (2002). Cultura organizacional: identidade, sedução e carisma? (3a ed.). Rio de Janeiro: Editora FGV.

Freitas, M. E. (2009). A mobilidade como novo capital simbólico ou sejamos nômades. Revista Organizações \& Sociedade, 16(49), 247-264, abr./jun.

Gallon, S., Scheffer, A. A. B., \& Bitencourt, B. M. (2014). A expatriação e o seu papel estratégico nas empresas internacionalizadas. InternexT - Revista Eletrônica de Negócios Internacionais da ESPM, 9(1), 38-56.

González, J. M. R., \& Oliveira, J. A. O. (2011). Os efeitos da expatriação sobre a identidade: estudo de caso. Cadernos EBAPE.BR, 9(4), 1122-1135, dez.

Homem, I. D., \& Tolfo, S. R. (2004). Gestão intercultural: perspectivas para o ajustamento de executivos expatriados. In: Encontro Anual da Associação Nacional de Pós-Graduação e Pesquisa em Administração, 28., 2004, Curitiba. Anais... 1-16.

Marcelo, J. F., \& Hayashi, M. C. P. I. (2013). Estudo bibliométrico sobre a produção científica no campo da Sociologia da Ciência. Revista Informação \& Informação, 18(3), 138-153.

Moreira, M. Z., Norões, J. L., \& Ogasavara, M. H. (2014). Framework da estratégia de expatriação no âmbito do indivíduo, da organização e do ambiente internacional. InternexT - Revista Eletrônica de Negócios Internacionais da ESPM, 9(1), 81-100.

Oliveira, A. C., Dórea, J. G., \& Domene, S. M. A. (1992). Bibliometria na avaliação da produção científica da área de nutrição registrada no Cibran: período de 1984-1989. Revista Ciência da Informação, 21(3), 239-242, set./dez.

Peltokorpi, V., \& Froese, F. (2009). Organizational expatriates and self-initiated expatriates: who adjusts better to work and life in Japan? The International Journal of Human Resource Management, 20(5), 1096-1112.

Rego, A., \& Cunha, M. P. E. (2009). Manual de gestão transcultural de Recursos Humanos. Lisboa: Editora RH. 
Ribeiro, H. C. M., \& Corrêa, R. (2014). 10 anos de pesquisa da Revista Brasileira de Inovação sob a ótica da bibliometria e da rede social. Revista Administração: Ensino e Pesquisa, 15(4), 729-767, dez.

Santos, A. R. (2007). Metodologia científica: a construção do conhecimento. (7a ed.). Rio de Janeiro: Lamparina.

Silva, E. L., \& Menezes, E. M. (2005). Metodologia da pesquisa e elaboração de dissertação. (4a ed.). Florianópolis: UFSC.

Spanger, M. A. F. C. (2012). Glamour e sombras na expatriação de executivos e executivas globais: intercorrências no trabalho e na família. Tese de Doutorado em Tecnologia. Universidade Tecnológica Federal do Paraná, Curitiba, Brasil.

Suutari, V., \& Brewster, C. (2000). Making their own way: international experience through selfinitiated foreign assignments. Journal of World Business, 35(4), 417-436.

Tanure, B., Evans, P., \& Pucik, V. (2007). A gestão de pessoas no Brasil: Virtudes e Pecados Capitais. Estudos de Caso. Rio de Janeiro: Elsevier.

Vanti, N. A. P. (2002). Da bibliometria à webometria: uma exploração conceitual dos mecanismos utilizados para medir o registro da informação e a difusão do conhecimento. Ciência da Informação, Brasília, 31(2), 152-162, maio/ago. 